\title{
Estudiando la importancia de las mujeres maestras del Paraguay desde la educación artística
} Studying the Importance of Female Teachers in Paraguay from Art Education Estudando a importância das professoras no Paraguai a partir da educação artística

Ricard Huerta

Universitat de València, España ricard.huerta@uv.es https://orcid.org/0000-0002-1430-3198

\section{Resumen}

El proyecto Mujeres Maestras es un homenaje a las docentes. Es una investigación educativa y artística que tiene como objetivo abordar la identidad de las mujeres que se dedican a la enseñanza. Utilizamos una metodología plural que combina estudios de caso, narraciones personales y artography. Se trata de un trabajo cualitativo y artístico. El proyecto busca unir intereses entre la universidad, los centros educativos y los museos. En Mujeres Maestras del Paraguay se destacan las diferencias experimentadas por las docentes en las escuelas públicas y privadas, aunque los resultados artísticos de la propuesta han generado intersecciones entre ambas realidades. Particularidades como el uso del guaraní, el interés por el trabajo bien hecho, o la atracción por la naturaleza, están relacionadas íntimamente con estas maestras y con la tradición de las artesanas del país. Como parte de los resultados, se presenta una selección de piezas de arte que se realizaron con motivo del proyecto y que se unen a las narrativas de las propias historias de las maestras.

Palabras clave: arte, docencia, educación, investigación, narrativas, Paraguay. 


\section{Abstract}

Women Teacher Project is a tribute to teachers. It is an educational and artistic research that aims to approach the identity of women who are dedicated to teaching. A plural methodology combines case studies, personal narratives and artography. This work is qualitative and artistic. The project seeks to unite interests between the university, educational centers and museums. In Women Teacher of Paraguay the differences experienced by teachers in public and private schools are highlighted, although the art results of the proposal have generated intersections between these realities. Particularities such as the use of Guarani, a job well done or the attraction to nature are related to these teachers with the artisans of the country. As part of the results, a selection of art pieces of the project and stories of the teachers is presented.

Keywords: art, teaching, education, research, narratives, Paraguay.

\section{Resumo}

O projeto Mulheres Professoras é uma homenagem aos professores. É uma pesquisa educacional e artística que visa abordar a identidade de mulheres dedicadas ao ensino. Utilizamos uma metodologia plural que combina estudos de caso, histórias pessoais e artography. Nosso trabalho é qualitativo e artístico. O projeto busca unir interesses entre a universidade, os centros educacionais e os museus. Nas professoras do Paraguai, destacamos as diferenças vivenciadas pelas professoras de escolas públicas e privadas, embora os resultados artísticos da proposta tenham gerado interseções entre as duas realidades. Particularidades como o uso do guarani, o grande interesse em um trabalho bem feito ou a atração pela natureza estão intimamente relacionadas a esses professores e à tradição dos artesãos do país. Apresentamos uma seleção de peças de arte que foram feitas para o projeto e que se juntam às narrativas das histórias dos próprios professores.

Palavras chave: arte, ensino, educação, pesquisa, narrativas, Paraguai.

Fecha Recepción: Abril 2020

Fecha Aceptación: Septiembre 2020 


\section{Introducción}

El proyecto Mujeres Maestras plantea cuestiones de identidad docente, de modo que nos acerca a las opiniones de las maestras al tiempo que reclama una mayor interacción entre los diferentes tipos de instituciones (universidad, escuela y museo). La investigación forma parte del Proyecto Internacional Mujeres Maestras, generado por el Grupo Creari de Investigación en Pedagogías Culturales (GIUV2013-103) de la Universidad de Valencia (España). Proponemos inicialmente una recogida de datos, desde la perspectiva investigadora de las narrativas personales, mediante entrevistas y la observación participante. La aportación en imágenes se resuelve de forma creativa a través de instalaciones artísticas participativas. Después de pasar por países como Chile, Uruguay, Bélgica, España, Perú, Colombia, Ecuador, Cuba, Brasil, Portugal y Argentina, el proyecto recae en Paraguay de la mano de la Universidad Columbia del Paraguay y el Centro Educativo Los Laureles (CEL), un centro universitario y un colegio con alumnado de primaria. Al acercarnos a las realidades educativas de Paraguay, utilizando la investigación educativa basada en las artes, ofrecemos un homenaje a las maestras y profundizamos en la realidad del amplio colectivo de las docentes de este país. Incorporamos acciones artísticas, creación de imágenes y poéticas visuales, con referencias que provienen del campo de las artes, la educación, la estética y la etnografía. Este tipo de investigación puede servir para mejorar la práctica de la educación artística en la escuela primaria, y también para reforzar el papel de las docentes en el marco educativo.

La trayectoria internacional del proyecto continúa, está vivo desde hace 15 años, de modo que el proyecto ha ido creciendo, enriqueciéndose y actualizándose. Este homenaje a las mujeres que se dedican a la enseñanza nos ofrece las opiniones de artistas, estudiantes y maestras. Inicialmente se lleva a cabo un trabajo exhaustivo de recopilación de datos, desde una perspectiva académica. En las entrevistas descubrimos historias fascinantes. Nos sorprenden con sus ideas, compartimos sus deseos de tener una mayor presencia como profesionales involucradas, y las apoyamos para lograr un reconocimiento social digno como docentes, como profesionales de la educación (Kunhardt, 2020). Reclamamos un espíritu crítico y promovemos la reflexión sobre las docentes como intelectuales, dada la delicada situación que padecen en muchos lugares con diversas problemáticas, en función de cada país. Henry Giroux propuso la redefinición del rol del maestro como intelectual público, a la vez que denunció el 


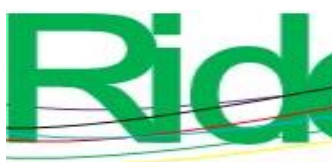

creciente número de personas que sufren dificultades, sufrimiento e incluso exclusión. Las educadoras enfrentan importantes problemas sociales, lo cual les obliga a defender la educación como una esfera democrática de importancia pública (Giroux, 2015), algo en lo que nosotros creemos firmemente.

El proyecto fue presentado en el Espace Atrium Hall del Parlamento Europeo en Bruselas con el título de Mujeres Maestras de Europa. Se trataba de llevar la voz de las docentes al foro de la entidad representativa más grande del continente europeo, para sensibilizar así a los responsables de las políticas educativas sobre la necesidad de escuchar a este grupo tan importante y tan invisible (Donaire, 2012). Representaba una novedad, en el caso de Bruselas, poder escuchar a los parlamentarios europeos, que se implicaron en la defensa del conjunto de las mujeres educadoras, teniendo en cuenta que en muchos casos las docentes deben enfrentarse a situaciones de precariedad realmente dolorosas (Zafra, 2017).

\section{Metodología}

En esta línea de trabajo y reflexión, nos sentimos muy cercanos a la propuesta que actualmente conocemos como artography, que ha sido difundida como metodología por Rita Irwin. Se trata de un modelo de investigación que une los procesos de las artes sin perder de vista nuestra faceta como educadores ni tampoco nuestra visión como investigadores. El término artography implica sentirse, al mismo tiempo, artista, educador e investigador, ya que las tres letras iniciales conjugan los tres elementos que se integran en él: la $a$ de artist, la $r$ de researcher y la $t$ de teacher (Irwin, 2013).

El estudio se basa en nuestra participación personal y profesional desde diferentes ámbitos relacionados, como la práctica artística, la formación del profesorado y la pedagogía para museos y entornos patrimoniales. Proponemos un modelo de investigación que nos permite conocer mejor al grupo de educadoras, al poder escuchar sus problemas (Giroux, 2013). La observación participante y las narraciones personales son nuestras principales fuentes de información. Realizamos entrevistas semiestructuradas y las grabamos en video (Rivas, Hernández y Sancho, 2012). Dichas grabaciones se publican más tarde en formato audiovisual, como elemento documental que servirá para incorporarlo al conjunto de la exposición. Un ejemplo de estos documentales lo podemos ver en el enlace https://vimeo.com/215170718 donde escuchamos las voces de las mujeres entrevistadas en Perú. La metodología que seguimos 
parte de los estudios de caso, y se especifica en las narrativas personales. Es un esquema de corte cualitativo (Stake, 1995) combinado con la investigación educativa basada en las artes.

Elaboramos resultados artísticos vinculados a la experiencia sobre las identidades docentes desde la educación artística (Huerta, 2012). Somos conscientes de la complejidad de integrar la reflexión educativa y la creación artística, pero entre nuestros argumentos más poderosos están las imágenes (Duncum, 2015). Las imágenes abordan el mundo de los docentes desde sus propias representaciones visuales, lo que significa generar un marco adecuado para diferentes realidades geográficas (Huerta, 2018). En el caso de Paraguay, el papel decisivo de las mujeres en las sucesivas reconstrucciones del país es algo que para cualquier persona de otro continente impacta sobremanera (Secretaría Nacional de Cultura, 2016).

Esta investigación se plantea como un estudio de caso, en el que la recogida de datos parte de la información conseguida mediante entrevistas y observación participante. También aportamos un importante componente de significado al incorporar la investigación basada en las artes como estrategia creativa. Los resultados artísticos que se consiguen, y que posteriormente son expuestos al público en un museo, nos permiten concebir una idea de la investigación mucho más cercana a la creación artística, y extender así la noción de investigación al territorio de la creatividad, implicando conceptos cuyos significados parten de actuaciones y experiencias de calado artístico. El enfoque es también de tipo etnográfico, ya que la finalidad es conocer fenómenos sociales desde la perspectiva de quienes viven dichos acontecimientos (Lucas, Trabajo y Borghi, 2020). La implicación política y social resulta fundamental para poder abordar cuestiones candentes (Hamlin y Fusaro, 2018). Tomamos la metodología cualitativa como marco de referencia, teniendo en cuenta el fenómeno en su conjunto, desde planteamientos epistemológicos flexibles, utilizando distintas técnicas para obtener los datos (entrevistas, encuestas, fotografías) y posteriormente generar imágenes.

Consideramos las narrativas como fuente inspiradora, especialmente las centradas en el ser humano, en sus intenciones, deseos y necesidades. La investigación permite ensamblar tres paradigmas (interpretativo, empirista y crítico), puesto que partimos de las experiencias de las propias maestras, indagamos en los problemas sociales (Hernández, Pacheco, Liranzo y Jiménez, 2018) y expresamos mediante obras de arte lo que transmiten con sus opiniones. El diálogo, la observación y la observación participante dan cuenta de la experiencia vivenciada (Stake, 1995). Utilizamos las artes como un método, como una 


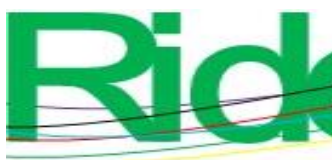

Revista Iberoamericana para la

Investigación y el Desarrollo Educativo

ISSN $2007-7467$

forma de análisis dentro de la investigación cualitativa; investigamos desde la propia experiencia artística (Dewey, 2008); indagamos sobre la creatividad y su interpretación, lo que, no está de más decir, fortalece la relación entre profesorado y alumnado; desde situaciones específicas, utilizamos elementos personales y colectivos de la experiencia cultural, ya que las artes llevan el "hacer" al campo de la investigación, y transforman sentimientos, pensamientos e imágenes en formas estéticas. La investigación basada en las artes busca otras maneras de mirar y representar la experiencia. Es por ello por lo que la utilización de representaciones artísticas de carácter visual constituye uno de sus principales referentes (Hernández, 2008).

En este artículo empleamos textos e imágenes que interactúan; en ambos casos adquieren un papel decisivo. No se trata de explicar las imágenes mediante los textos, sino de hablar de las imágenes a partir de ellas, como ocurre cuando en autoetnografía decimos que "no se trata de hablar de mí, sino desde mí". De este modo, las obras permiten estudiar sistemáticamente los recuerdos de un trabajo cooperado, en un contexto social y político contemporáneo, mediante la reflexión educativa y la investigación con métodos artísticos. La investigación basada en las artes nos aporta reflexividad: acorta las distancias entre el yo y el nosotros. También es memorable, puesto que no puede ser fácilmente ignorada, de modo que demanda nuestra atención. Como dice Fernando Hernández (2008, p. 108): "El arte es una experiencia, que de manera simultánea atrae nuestros sentidos, emociones e intelecto".

Utilizamos planteamientos creativos y elaboramos representaciones artísticas para fomentar procesos innovadores mediante la experimentación, con prácticas educativas en las que el arte tiene una presencia fundamental (Huerta, 2019). Las representaciones facilitan la empatía y nos permiten ver a través de la mirada de la investigación en artes e incorporar la experiencia vivida como elemento transgresor. Reflexionando sobre el poder de la imagen, reivindicando a colectivos que han sido silenciados a lo largo de la historia, convertimos lo ordinario en extraordinario.

\section{Resultados}

El presente artículo desarrolla especialmente la experiencia del proyecto en Paraguay. Antes, sin embargo, hacemos un breve repaso inicial a lo que ha sido la trayectoria de Mujeres Maestras. Esto para evidenciar que, si bien el proyecto mantiene una intención similar, hay particularidades en cada país donde se lleva a cabo. 


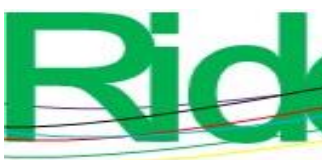

Revista Iberoamericana para la Investigación y el Desarrollo Educativo ISSN 2007 - 7467

Santiago de Chile es una ciudad fascinante. Tuvimos la oportunidad de presentar el proyecto Mujeres Maestras de Chile en el Museo Artequin, una entidad muy preocupada por la educación en artes.

Figura 1. Pintura dedicada a Paola Guerrero. Serie Mujeres Maestras de Chile

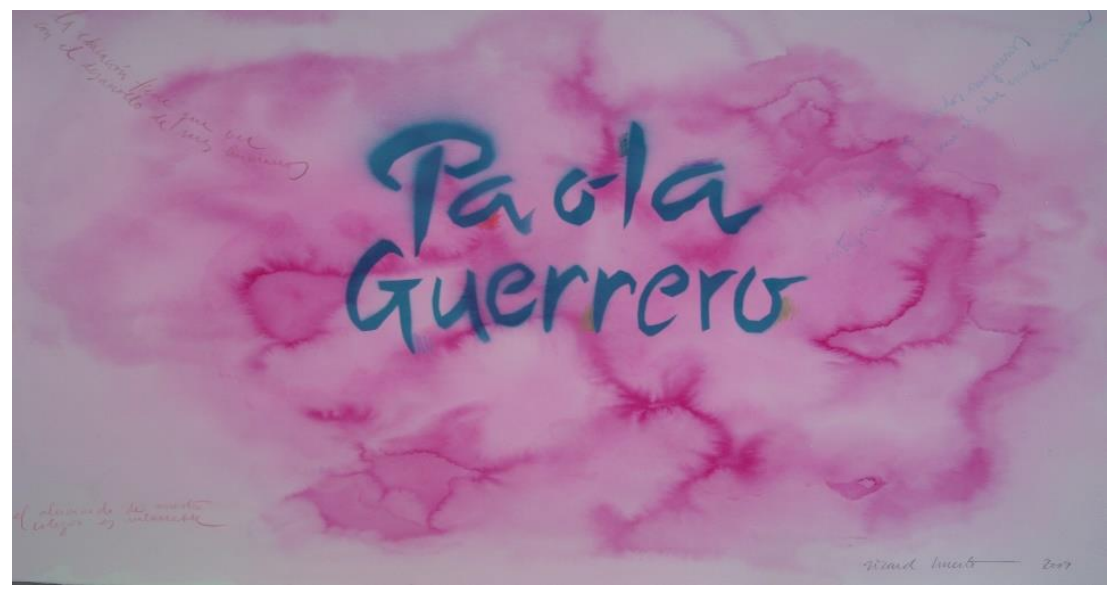

Fuente: Mujeres Maestras de Chile

Las declaraciones de las maestras chilenas son muy emotivas, considerando la vigencia histórica del episodio sangriento de la dictadura, un drama que aún pesa en la memoria colectiva. Muchas mujeres sufrieron persecución por parte del régimen militar. Algunas perdieron a sus familiares: "Mi padre estaba recluido en el Estadio Nacional por ser partidario del gobierno de Allende. Luego desapareció y el ejército declaró haberlo arrojado al mar", nos cuenta con dolor una maestra chilena. Otras son conscientes de su papel esencial como educadoras: "Una vez pensé que a través de la educación podría transformar el mundo y por eso me convertí en maestra, pero hoy creo que la educación puede ayudar a transformar a las personas y que esas personas, tal vez, pueden transformar la sociedad", nos comenta una docente que ha tenido responsabilidades en el Ministerio de Educación. 


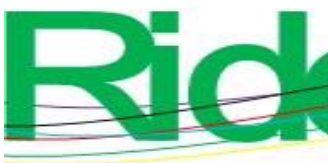

Revista Iberoamericana para la Investigación y el Desarrollo Educativo ISSN $2007-7467$

Figura 2. Pintura dedicada a Marisa Lopez. Serie Mujeres Maestras del Uruguay

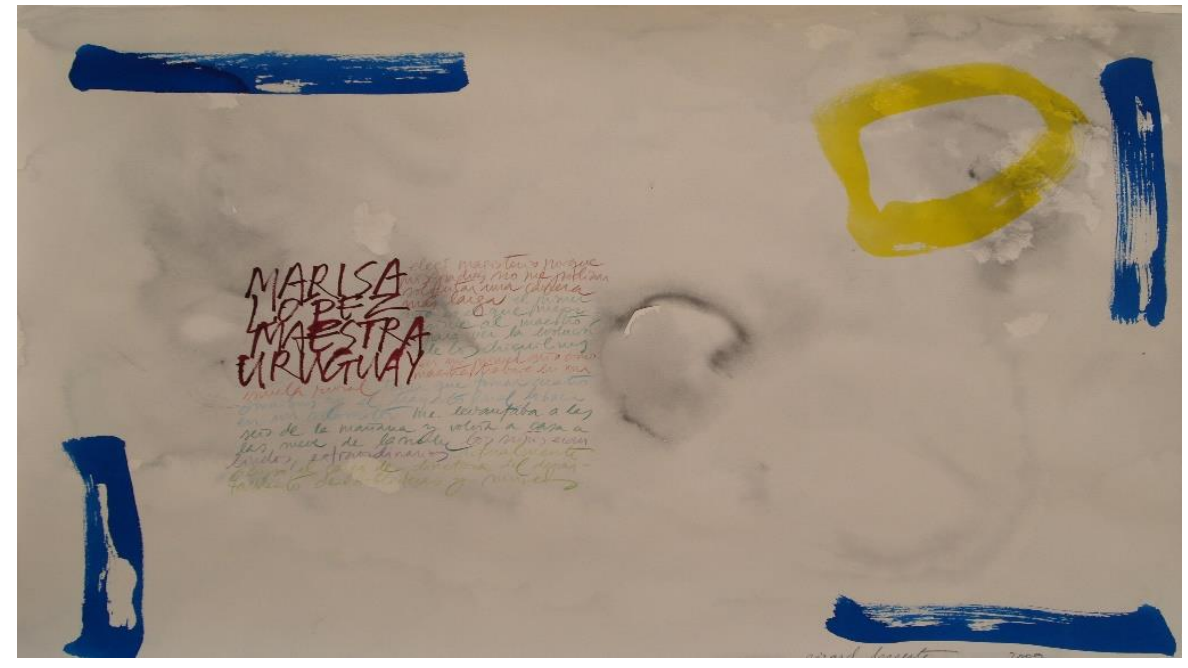

Fuente: Mujeres Maestras de Uruguay

Al llevar a cabo el proyecto en la ciudad de Montevideo, pudimos comprobar el peso específico que el grupo de las docentes adquiere en un país como Uruguay, pequeño en tamaño, pero con una gran tradición tanto en logros sociales como en la defensa de los derechos humanos. Participaron numerosas entidades educativas y culturales. Pudimos asistir a conciertos, conferencias, espectáculos de películas y otras actividades en las que se defendió en particular el papel esencial de las maestras, y en general el del sistema educativo público. Llegaron estudiantes de todos los niveles que participaron activamente en los eventos: dibujaron a sus maestras y comentaron cómo percibían el trabajo de las docentes. En Montevideo hay una biblioteca y un museo de la educación, ambas instituciones administradas exclusivamente por mujeres maestras. Las maestras se sorprenden de que nos interesemos por sus problemas (Alonso, 2016). Y nos dicen que nunca antes habían utilizado el arte como estrategia de reivindicación del colectivo.

Al revisar los resultados del proyecto en España, detectamos las carencias y alentamos nuevas derivas (Albero y Arriaga, 2018). En el Museo de la Universidad de Alicante (MUA), los niños y las niñas fueron quienes instalaron sus dibujos en las paredes y comentaron cada uno de ellos. Pudimos ver hasta qué punto era importante para este alumnado que sus dibujos se exhibieran de manera destacada. Los estudiantes están evolucionando hacia posiciones más participativas, lo que hace que incluso los más pequeños quieran dar sus opiniones y defender sus criterios. Son los y las estudiantes quienes animan a sus padres, madres y familiares a visitar la exposición. Habiendo expuesto su trabajo en una institución, como es la sala de exposiciones del MUA, quieren poder explicar a sus mayores cómo han vivido la experiencia (Álvarez, 2019). El éxito 
del público en las exposiciones está estrechamente relacionado con este factor. Familiares y amistades van al museo para que cada niño o niña les muestre y les explique su dibujo.

Figura 3. Pintura dedicada a Jan Morris. Serie Alfabeto de las Mujeres Maestras

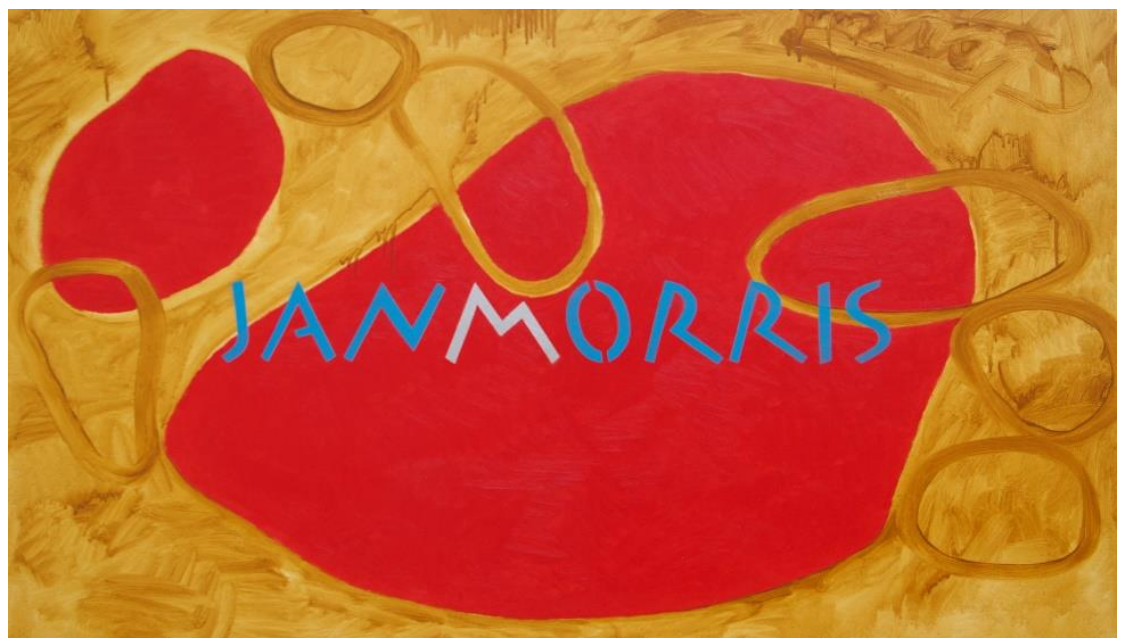

Fuente: Alfabeto de las Mujeres Maestras

Indagamos sobre las identidades docentes a partir de narrativas personales (Rivas et al., 2012). Buscamos referencias en las voces de las propias docentes, algo que posteriormente analizamos y describimos desde la cultura visual como paradigma. Respecto a la perspectiva de las historias de vida, Fernando Hernández (2008) afirma que es un campo de estudio que plantea desafíos, que no se puede aplicar como una fórmula a la intención del investigador, y que se trata de una opción vinculada al giro que tomó la investigación en humanidades y ciencias sociales desde 1970. Hablamos con personas de diferentes centros educativos, e intercambiamos con estas mujeres actividades e intereses durante el proceso, mediante prácticas artísticas y reflexión estética (Costa, 2018). Mantenemos una estrecha relación con las docentes mientras dura el proceso de recogida de datos, lo que nos permite conocer sus opiniones y disponer de información desde la cercanía. Accedemos a sus problemas observando factores como las repercusiones emocionales o los sentimientos, elementos que adquieren una presencia relevante en muchos aspectos cotidianos de la profesión docente (Rolling, 2017).

Al utilizar la creación artística como medio expresivo, generamos una actividad de carácter social, político y cultural. Establecemos como criterio la participación personal, lo cual nos ayuda a mantener un contacto vivo con la realidad que nos rodea. Sin embargo, debido a que la investigación educativa basada en las artes tiene como recurso más evidente el uso de las imágenes, debemos saber cómo manejar este discurso visual, a la vez que exploramos los problemas de los grupos vulnerables (Huerta, 
Domínguez y Barbosa, 2017). Las poéticas visuales se convierten aquí en efervescencias creativas y de reivindicación (Monterroza, Buelvas y Urango, 2019).

En Colombia, la crueldad que provoca la pobreza, junto con el estigma del machismo, se suman a la violencia de las armas. Ser maestro en un entorno desfavorecido requiere mucha implicación, y valor, especialmente en entornos inseguros y con población vulnerable (Freire, 2015).

Figura 4. Pintura dedicada a Diana Marcela. Serie Mujeres Maestras de Colombia

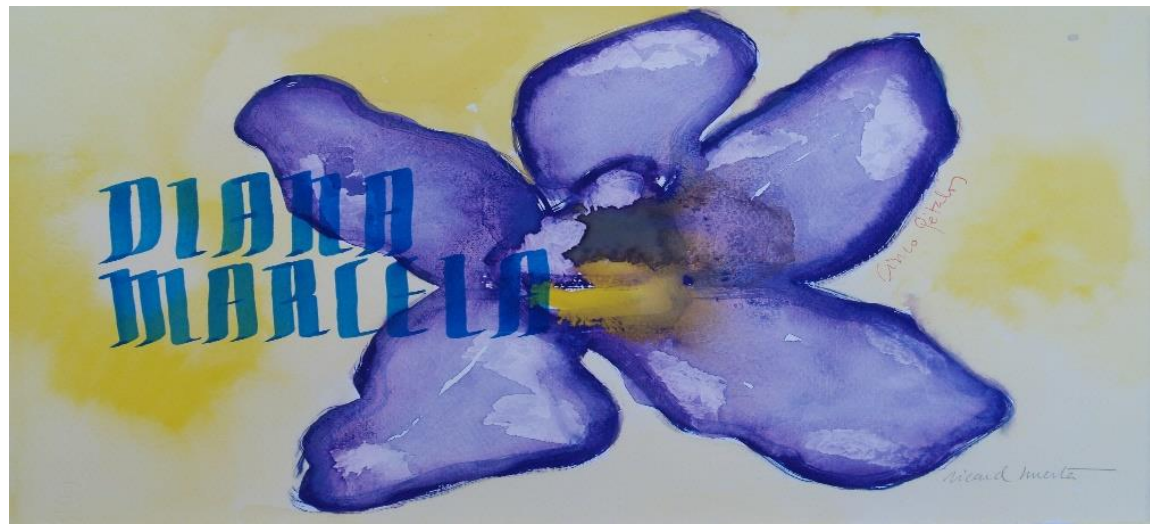

Fuente: Mujeres Maestras de Colombia

Ser docente en Colombia es una tarea que implica una gran dificultad. Pilar Méndez Rivera (2016) advierte sobre las maestras que "su participación en la vida pública, en estrecha relación con otras implicaciones, le obliga a posicionarse en la compleja red de relaciones de poder que se entrelazan en la confluencia de los campos político, educativo y social" (p. 18). A los problemas laborales del grupo se agregan elementos que dificultan el ejercicio profesional, tal y como la precaria situación de las familias de los estudiantes, o incluso el mal estado de las instalaciones donde trabajan.

La mayoría de profesionales de la educación que se dedican a atender alumnado de la primera infancia y la escuela primaria son mujeres. En este sentido, el aspecto visual de las profesoras incluye numerosas cuestiones a evaluar, por ejemplo, la "imagen" de las propias docentes: ¿cómo las vemos? ¿cómo las ve el alumnado? ¿cómo se ven ellas a sí mismas?, ¿cómo les gustaría ser vistas? (Greteman, 2017). Entre los objetivos del proyecto, destacamos la intención de fortalecer la educación artística al reflexionar sobre las identidades de la enseñanza a través de un espíritu creativo, con deriva social; dibujando, pintando, haciendo fotografías y videos y exponiendo los resultados en un museo, adaptamos estas identidades a los nuevos ritmos. Hacemos visible el problema de las maestras que se dedican a la enseñanza, incorporando temas como el papel de la 


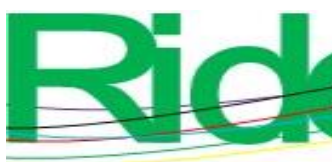

Revista Iberoamericana para la Investigación y el Desarrollo Educativo ISSN $2007-7467$

conciliación familiar y laboral de las mujeres (Alonso, Jardón y Lifante, 2019). El retrato de cada maestra está construido a partir de las letras de su nombre. De este modo, rompemos desde el inicio con los esquemas y los prejuicios establecidos en relación con la belleza femenina y los cánones habituales.

Figura 5. Pintura dedicada a Nora Cepeda. Serie Mujeres Maestras del Perú

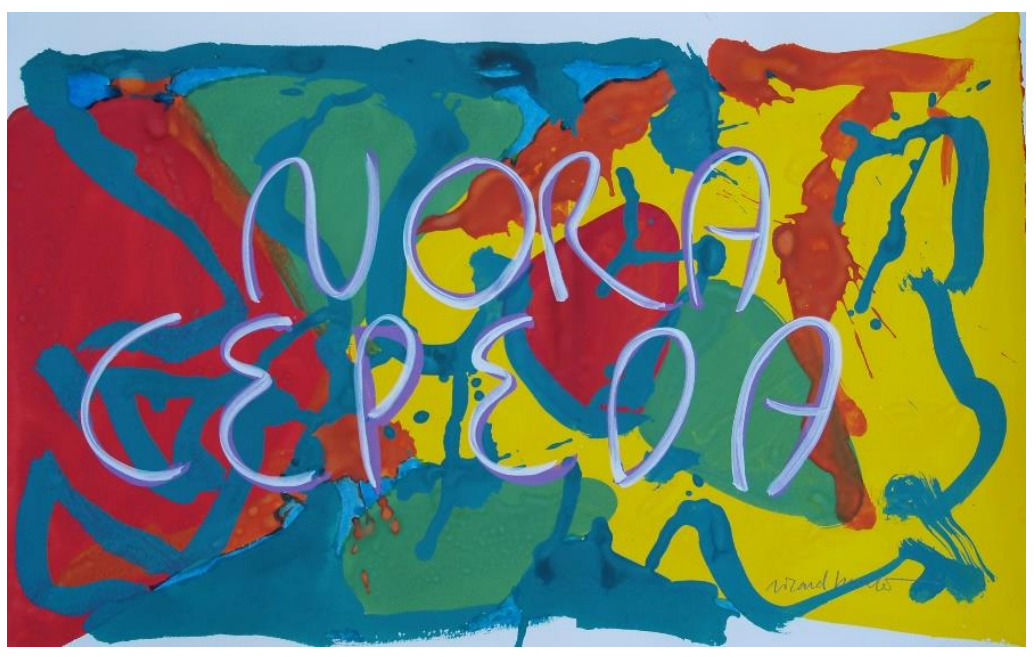

Fuente: Mujeres Maestras del Paraguay

\section{Encuentros creativos con las mujeres maestras del Paraguay}

Las maestras nos informan sobre sus circunstancias como docentes a través de sus narraciones personales, a través de sus experiencias y opiniones. El proceso de investigación artística se nutre de la mirada y de la observación participante, auscultando pacientemente la experiencia de aquellas que en realidad están investigando sobre sus propias preocupaciones y necesidades, ya que nosotros también queremos aprender de la experiencia de estas mujeres. Hablamos con maestras que representan a distintos sectores sociales y económicos. Las convertimos en protagonistas del discurso expositivo. Los colores y los gráficos son parte de un marco capaz de crear, desde la cultura visual, una nueva mirada hacia los docentes, y renovar la percepción de los colectivos de profesionales que se dedican a la educación. 
Figura 6. Trabajo dedicado a Carolina Pederzani. Serie Mujeres Maestras del Paraguay

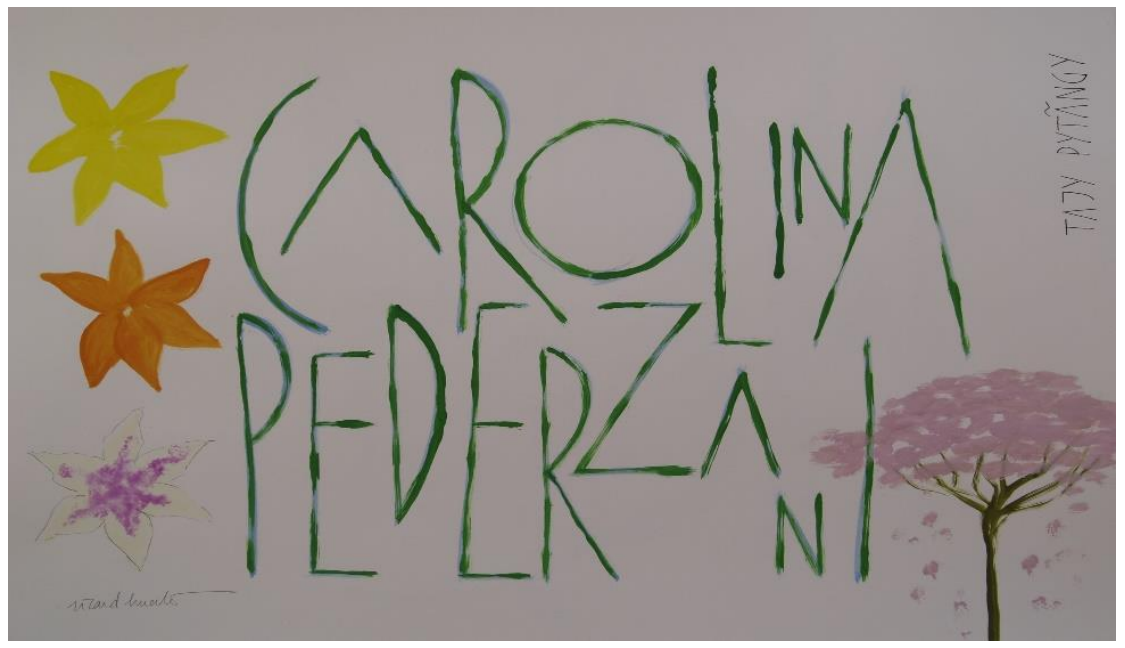

Fuente: Mujeres Maestras del Paraguay

Escuchamos historias de profesoras con más edad, y también de profesionales que, a pesar de su juventud, cuentan con larga experiencia. Tratamos de acercar las artes y la educación artística a las actividades mediante acciones que fomentan la unión y la colaboración entre maestras, escuelas y museos. Con estas acciones, destacamos las realidades en las que nos movemos y aportamos ideas para mejorar nuestras formas de educar. En los retratos de los maestros usamos sus nombres: símbolos gráficos, letras del alfabeto, que en cierta medida los define. Y mientras el alfabeto da forma a la singularidad de cada maestro a partir de la composición tipográfica, las manos de los niños y las niñas los interpretan con sus composiciones plásticas en las que se refleja el enorme afecto que expresan por estas profesionales docentes (Eustáquio, 2017). Los retratos de las maestras son un medio para transmitir nuestro respeto y admiración por los esfuerzos de estas mujeres trabajadoras de la cultura (Ramon, 2019). El hecho de implicar a su alumnado en el homenaje refuerza la admiración y el respeto de los más pequeños por sus maestras. 
Figura 7. Pintura dedicada a Eva Quevedo. Serie Mujeres Maestras del Paraguay

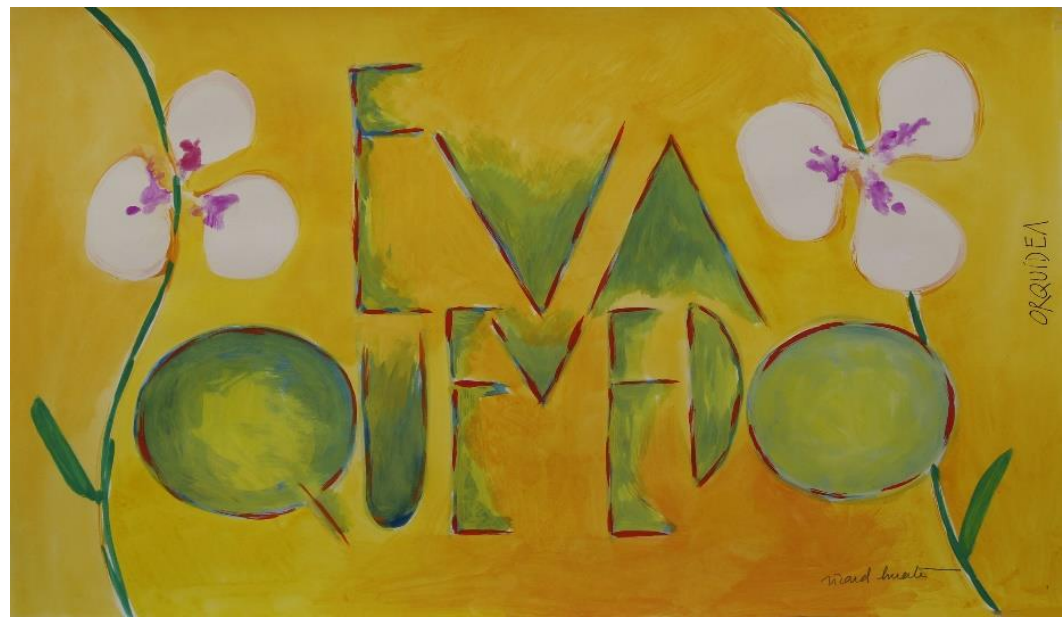

Fuente: Mujeres Maestras del Paraguay

El proyecto toma un perfil distinto en cada país. En el caso de Paraguay, debido a la abrumadora presencia de la naturaleza en el paisaje, le pedimos a cada maestra que nos dijera cuál era su flor, planta, árbol o elemento natural favorito (Capdevila, 2016). Laura Maldonado eligió la flor de santa Rita (buganvilla), por lo que esta flor funciona como motivo de la composición del retrato. Laura dirige el nivel inicial del CEL, donde ha trabajado durante 24 años, el tiempo que ha dedicado al ejercicio de la docencia. Algunas maestras eligieron animales (gato, búho, mariquita, abeja), mientras que otras optaron por elementos conceptuales vinculados al territorio (tierra, horizonte, arena). Olga Molina nos enseñó su predilección por la línea del horizonte, aquella que une al mar y al cielo. Como en el idioma guaraní el concepto de mar no es traducible, se eligió "gran agua” (yguasu). Paraguay no tiene salida al mar, es un país rodeado por tierra en todas sus fronteras.

En cada dibujo, el concepto elegido en el idioma guaraní se expresa en un lado. Una de las características decisivas de la cultura paraguaya es el guaraní, por lo que queríamos registrar esta poderosa idiosincrasia en cada pintura de la serie. El árbol con más seguidores y preferido de las maestras es el tajý (lapacho), aunque Edit Vera y otras optaron por la flor rosa tajý (tajý pytãngy). 


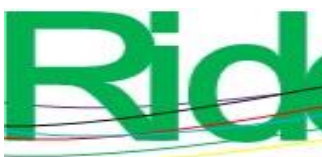

Figure 8. Composición dedicada a la maestra Beatriz Martínez. Serie Mujeres Maestras del Paraguay

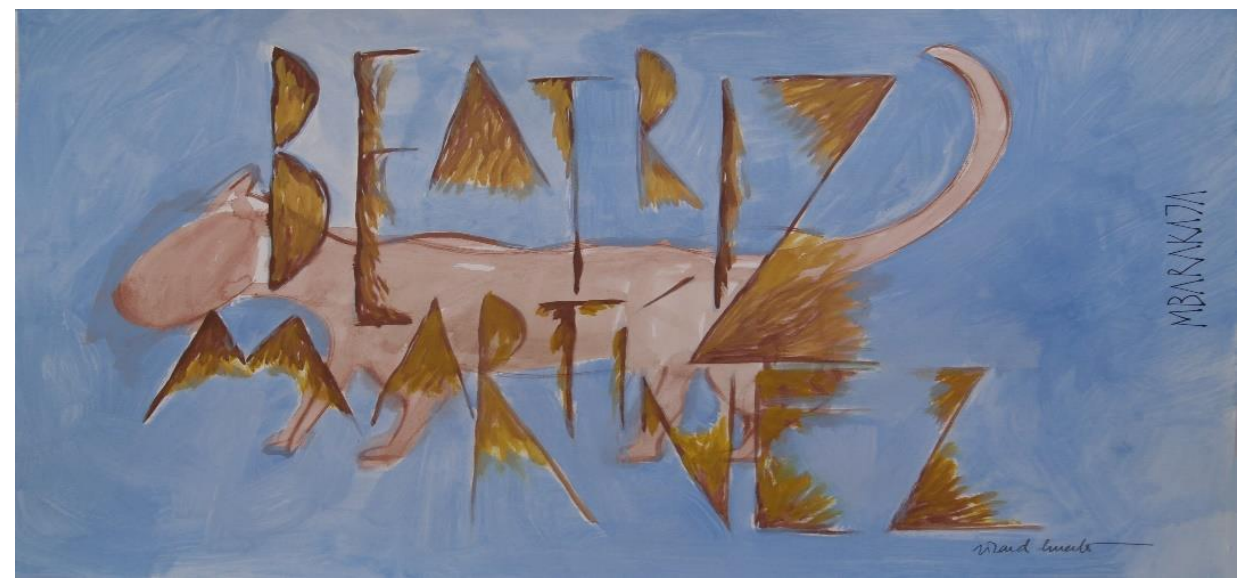

Fuente: Mujeres Maestras del Paraguay

La interpretación artística de cada maestra está sustentada en la información que nos ofrecieron durante la entrevista y a través de sus textos escritos. Luego de haber podido compartir experiencias y conversaciones en el CEL durante varias semanas, tuvimos la oportunidad de conocerlas mejor, ya que el taller donde se ejecutaron las pinturas estaba situado precisamente en las instalaciones de CEL, lo cual nos permitió también ampliar el diálogo con estudiantes y con el personal de servicios y administración del centro.

Para la selección de las docentes se tomaron en cuenta los antecedentes y la edad. Igualmente es necesario mencionar que se contó con la participación de tres centros educativos: uno privado, uno público y otro alternativo. Del CEL participaron Olga Molina, Claudia Saldívar, Susana Ortega, Margarita Vega, Laura Olivera, Delsy Cristaldo, Beatriz Martínez, Eva Quevedo y Laura Maldonado. De la Escuela Pública de la República de Panamá participaron las maestras Mariana Villalba, Ofelia Peralta, Edit Elizabeth Vera, Lilian Rosana Escobar, Rosana María Elena y Amalia Pamela Aquino, que estuvieron muy motivadas e involucradas en la experiencia. En nombre de la escuela Kunumí Areté de Areguá participaron Julia María Pineda, Lourdes Benítez, Cinthia Karina López, Ana Caballero, Carolina Pederzani y Noelia Buttice.

Las opiniones de las maestras paraguayas quedaron plasmadas en el video Mujeres Maestras de Paraguay, un documental en formato audiovisual que recoge las entrevistas y parte del proceso de trabajo. Además de contar con la edición de este documento audiovisual, se llevó a cabo un seminario participativo, en el que les pedimos a las maestras que relatasen experiencias personales. Para Laura Maldonado, ser maestra 
significa, "en primer lugar, transmitir amor al aprendizaje, demostrar felicidad en todo momento y compartir la vida cotidiana". Eva Quevedo quiso resaltar "la fuerza y el coraje que adquirió cuando fue despedida del cargo como directora general de la última institución donde trabajó”, después de lo cual decidió crear y dirigir su propio centro educativo. En esto radica la idea del artesano expuesta por la filosofía pragmatista americana: ser artesano es querer hacer las cosas bien (Sennett, 2008).

Figura 9. La maestra Ofelia Peralta junto a su retrato tipográfico en la exposición

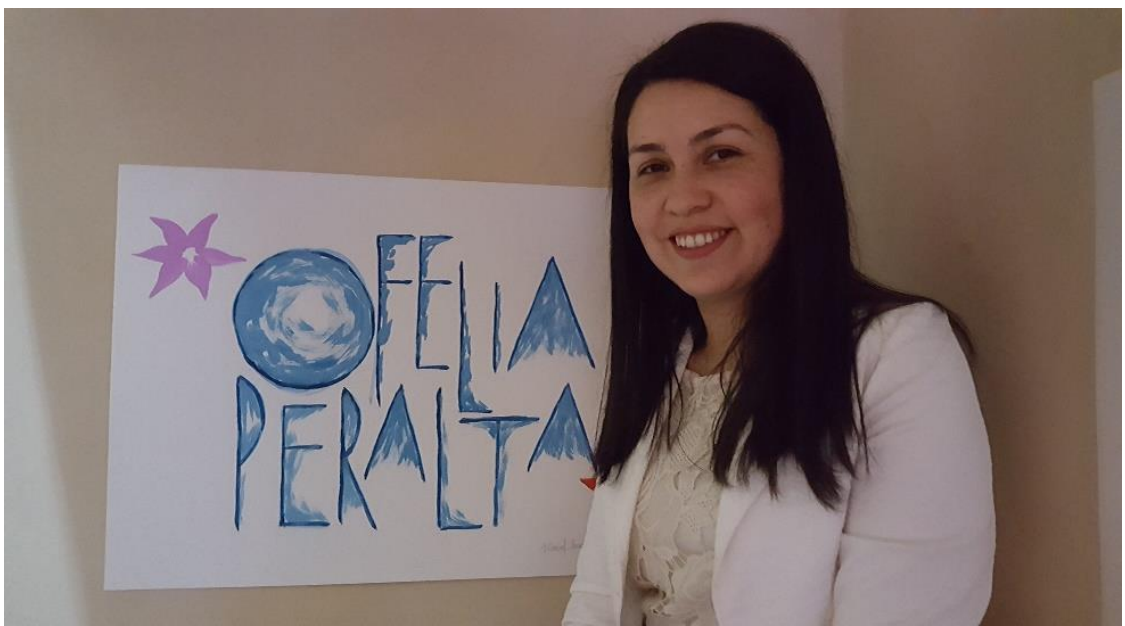

Fuente: Mujeres Maestras del Paraguay

Claudia Saldívar es la única maestra en su familia. Para ella, la enseñanza es "una profesión fascinante, porque me permite transmitir a los niños lo que sé y aprender de ellos". Laura Olivera sintió "ya de niña la vocación docente, cuando jugaba para ser maestra con sus hermanas". Siempre quiso trabajar con estudiantes con necesidades especiales y con especificidades curriculares. Esta opción vocacional la puede llevar a cabo ahora, ya que el CEL es un centro inclusivo, donde la diversidad es la clave del equilibrio. Desde que Beatriz Martínez era niña, su padre le inculcó la idea de ser maestra, y ella jugaba a serlo "improvisando una pizarra y escribiendo lecciones para mis amigos en esa pizarra". Amalia Pamela Aquino, maestra y licenciada en Psicología, destaca "la sinceridad de los niños para mostrar su amor". Ha trabajado durante 20 años en diferentes instituciones públicas y privadas, y considera que en la educación pública se debe dar más importancia al nivel inicial (Melo de Lima Santos, 2017). Lourdes Benítez se formó en comunicación y se dedica a la escritura creativa, a la literatura. Después de haber vivido como madre de una estudiante la experiencia educativa en Kunumí Areté, imparte talleres de comunicación allí mismo. Kunumí Areté es una escuela cooperativa en la que participan activamente los padres y las madres del alumnado. 


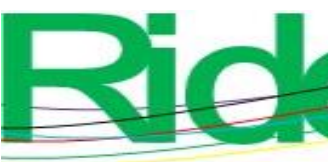

Revista Iberoamericana para la Investigación y el Desarrollo Educativo ISSN $2007-7467$

Hemos verificado las diferentes sensibilidades y propuestas que caracterizan a estas tres entidades educativas paraguayas, ya que cada una tiene una orientación muy particular (Escobar, 2011). Noelia Buttice explica que crearon la escuela Kunumí Areté para "acompañar a nuestros hijos e hijas en su crecimiento, porque queríamos pensar y sentir en la comunidad lo que era importante para nosotros”. Ana Caballero, también de Kunumí Areté, que estudió diseño gráfico y se dedica a las artes visuales, nos cuenta: "Mi inspiración para el trabajo es una escuela de arte de cuando yo era niña, la Escuela Municipal de Arte de Asunción, donde conocí a personas muy interesantes, a maestros innovadores, que trabajaban el arte de una manera lúdica, muy inspiradora". Esta inspiración y experiencia de su infancia la traslada actualmente a su tarea educativa por medio de historias y elementos comunes de la comunidad.

Para Delsy Cristaldo, del CEL, es muy inspirador poder impartir Comunicación (español) a estudiantes con diversidad funcional, tal es el caso de un estudiante con ceguera de quien se siente muy cercana, así como al resto de los niños, a quienes describe como "una pequeña caja de sorpresas"; valora positivamente la atmósfera de compañía del centro. Lilian Rosana Escobar Caballero, de la Escuela de la República de Panamá, maestra y licenciada en Educación, desde muy joven ya había considerado seriamente acceder a una plaza de maestra como funcionaria estatal. Primero pasó 12 años trabajando en instituciones privadas, lo cual le permitió alcanzar la puntuación requerida. Lilian nos recuerda la importancia de la teoría crítica de la enseñanza, especialmente cuando se trata de recibir un apoyo significativo de la autoridad educativa, animar en el acompañamiento a los padres o aumentar los valores de la sociedad (Carr y Kemmis, 2009).

Figura 10. Pintura dedicada a la maestra Laura Maldonado. Serie Mujeres Maestras del Paraguay

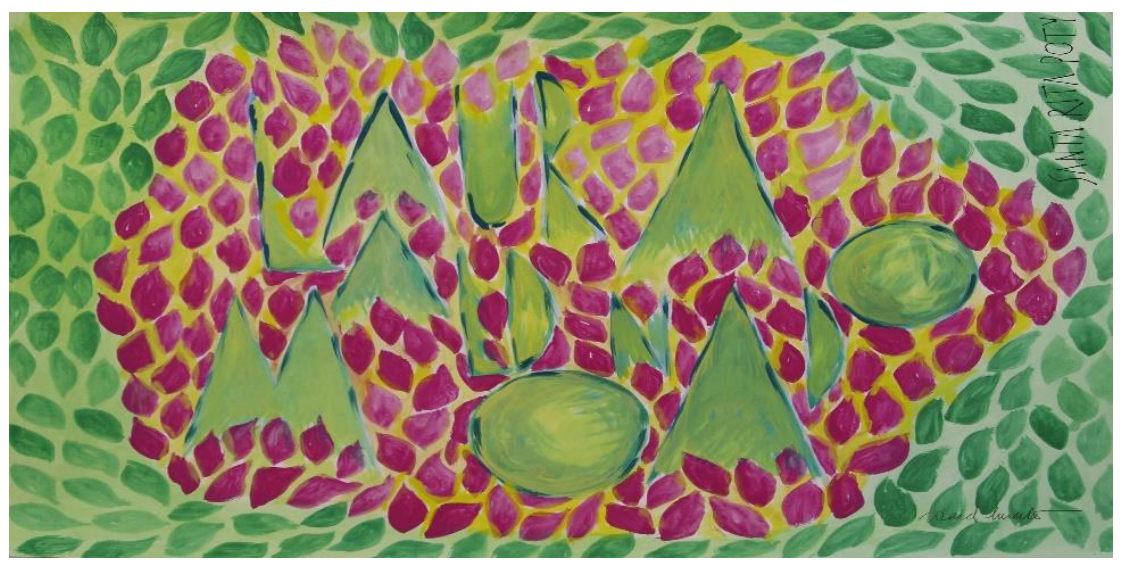

Fuente: Mujeres Maestras del Paraguay 


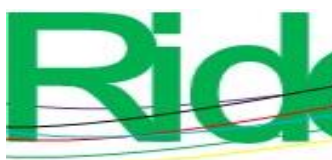

Revista Iberoamericana para la Investigación y el Desarrollo Educativo ISSN $2007-7467$

Algunas docentes exigen un mayor reconocimiento, tanto en términos de salario y seguridad económica como en la evaluación de las calificaciones, así como una capacitación constante para actualizar el conocimiento. Son conscientes del papel que ha adquirido la tecnología, y quieren que este aspecto se tenga en cuenta en los procesos de formación docente (Huerta, Alonso y Ramon, 2018). Rosana Esquivel, después de 20 años de experiencia docente, reconoce que el desgaste físico y emocional es grande, y se siente muy sola como maestra de nivel inicial; explica que el docente debe poner mucho de su parte, ya que los niños llegan con muchos problemas. Exige más apoyo de los padres y más interés del Estado, especialmente para casos de agotamiento y salud mental.

Karina López, una bailarina especializada en danza contemporánea, transfiere su conocimiento sobre las posibilidades expresivas del cuerpo a los estudiantes de Kunumí Areté. Olga Molina ha sido maestra durante 25 años y se ha enfocado en la enseñanza de talleres artísticos, especialmente de artes plásticas, algo que podría desarrollar como maestra del CEL, donde fue alentada a estudiar la carrera de artes. Laura Olivera se formó como química, y ha tenido que trabajar anteriormente en empresas y compañías químicas para poder cuidar de sus hijos cuando eran más pequeños. Pero finalmente ha vuelto a la enseñanza, algo que, para ella, es como su mundo, algo que siente muy de cerca. Laura eligió el jazmín como el elemento natural que la representaba.

Susana Ortega transmite sus impresiones a través del idioma guaraní. Al respecto, explica que es muy difícil traducir al español cuando se habla de conceptos o sentimientos de esta cultura. Su pasión por la enseñanza y la literatura le han empujado a transmitir sus ideas a través de libros y publicaciones, ediciones donde se esfuerza por dignificar la presencia de su idioma. En los dibujos de su alumnado reconocemos el cariño con el que interpretan el modo en que transmite los saberes del idioma y la filosofía guaraní, una cultura originaria de las tierras del Paraguay. 
Figura 11. La maestra Susana Ortega interpretada por su alumnado

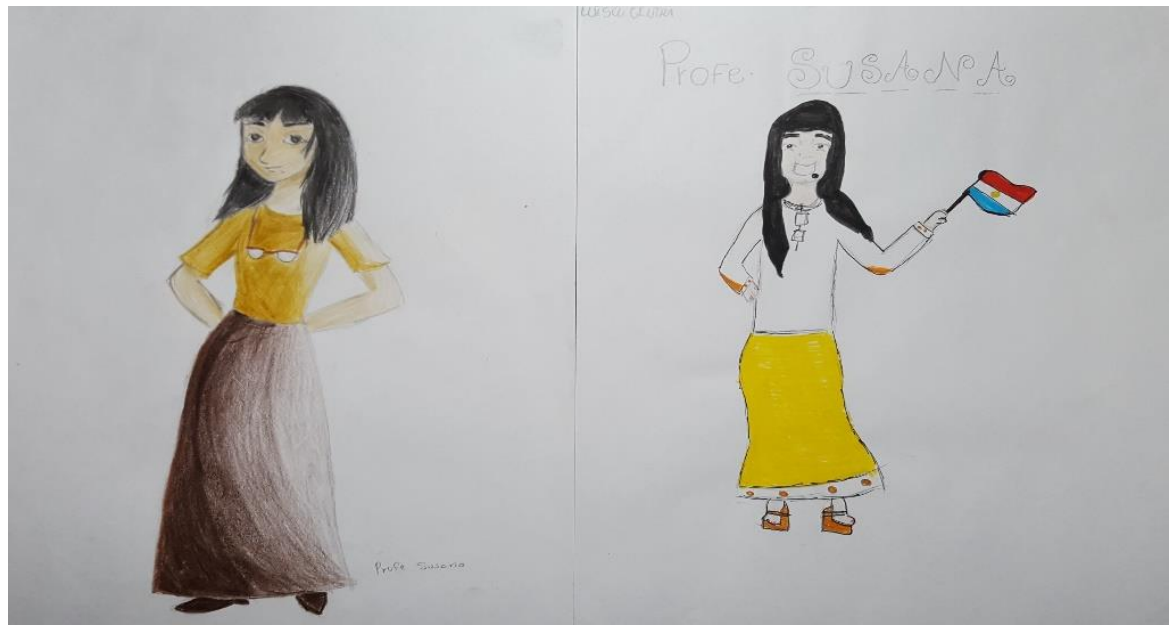

Fuente: Mujeres Maestras del Paraguay

Detectamos en Susana una alta implicación en todo aquello en lo que cree, ya que también transmite sentimientos y describe con vehemencia ideas, formas y palabras con las que el mundo puede transformarse. Su alegría es contagiosa, sus gestos elocuentes y su forma de difundir el espacio cultural guaraní es emotiva. Ella eligió la tierra (yvy avevo) como una razón determinante para su preferencia en relación con el medio ambiente natural (El Haddad et al., 2018).

Las opiniones del artista y del alumnado se unen a las opiniones de las maestras, que escuchamos a través de los videos. En las entrevistas se plantean preguntas abiertas, basadas en ideas como las siguientes: la razón por la cual decidieron ser maestras, los problemas que les preocupan tanto a nivel personal como laboral, así como de qué modo conciliar su vida familiar con las tareas de la enseñanza. La reflexión se extiende a una faceta conceptual, considerando el aspecto teórico desde la realidad artística misma. Mujeres Maestras del Paraguay permite una reflexión compuesta de ideas, sentimientos, imágenes y textos, y genera así acción y reflexión teórica (Elliott, 1991).

Para Carolina Pederzani, maestra de educación infantil en Kunumí Areté, es importante "convertirse en una niña más con ellos", refiriéndose a los estudiantes, ya que "todos tenemos a nuestro hijo adentro" para crear un "pequeño mundo hermoso". Julia Pineda, también de Kunumí Areté, valora positivamente "poder estar con niños al aire libre, escucharlos para aprender de ellos, que cualquier cosa puede ser un aprendizaje". Por su parte, Ofelia Peralta, hija de una maestra, trabaja en el tercer grado de primaria (aquí le llaman básica) en la Escuela de la República de Panamá. Aunque piensa que "ella aprende jugando", considera que "la profesión de educadora debe ejercerse como una 


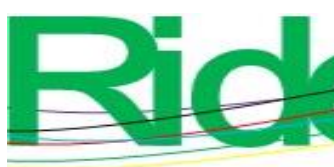

vocación", ya que "si no amas esa profesión, y más en Paraguay, es muy sacrificada", debido a que "la sociedad no reconoce nuestro trabajo".

Para Claudia Saldívar, una de las cuestiones clave es la inclusión, precisamente porque todos los estudiantes se benefician de tener y escuchar las experiencias de compañeros de clase que necesitan atención específica. Incluso nos cuenta que Álvaro Martínez, que trabaja en Teletón, ha sido su alumno. Margarita Vega, por otro lado, como licenciada en Ciencias en Educación, explica la enorme diferencia que significa trabajar en un centro público o en una escuela privada, ya que ella, durante más de 15 años, ha podido conocer ambas realidades. Un caso peculiar es el de la artesana Rosa Segovia, tejedora de ponchos de 60 alambres (una de las pocas profesionales que quedan), quien también decidió estudiar pedagogía y ahora es una maestra licenciada.

\section{Discusión}

El peso que adquieren en nuestras vidas las mujeres de las que aprendemos, de quienes recibimos importantes aportaciones, resulta invaluable; en nuestras investigaciones artísticas aportamos el reconocimiento que merece esta tarea vital y educativa. El tiempo compartido en Paraguay con el grupo de mujeres maestras de distintos centros educativos nos ha permitido acercarnos a sus realidades, analizar sus vivencias y sus rutinas cotidianas, comprobar hasta qué punto están implicadas en sus tareas docentes. Ellas nos ofrecen sus opiniones y nos transmiten sus ideas. Nosotros elaboramos documentos, y preparamos una exposición en la que se exhiben las pinturas realizadas, retratos de las protagonistas, y los dibujos que ha confeccionado el alumnado de estas maestras. Así, se logró un acercamiento a su imagen, a lo que son ellas, a través de las artes visuales. Las grabaciones de las maestras cuando nos comparten su visión particular del mundo en el que vive nos hablan, en conjunto, editadas y montadas, del Paraguay desde la perspectiva de sus profesoras. Todos estos resultados artísticos (dibujos infantiles, pinturas, video documental con entrevistas) se presentan en una exposición, una muestra en la que participa como anfitriona la Universidad Columbia del Paraguay.

La exposición y el resto de actividades pretenden generar un acercamiento al mundo de las maestras, a sus identidades, a sus inquietudes, desde diferentes puntos de vista. Se unen aquí diversas miradas: la del artista, la del alumnado y la opinión de las propias maestras que explican su visión del mundo en el que se involucran. La reflexión académica corre a cargo de un equipo de especialistas multidisciplinar, un grupo de 


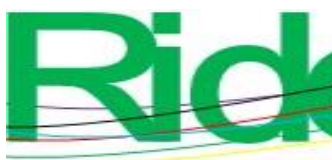

Revista Iberoamericana para la Investigación y el Desarrollo Educativo ISSN $2007-7467$

profesionales que articula todos estos elementos para presentarlos al público en la sala de exposiciones.

Conocer personalmente la dinámica de un grupo de docentes en Paraguay nos ha permitido establecer nuestros propios criterios sobre los modelos educativos del país, así como generar una experiencia enriquecedora al entrevistarlas y representarlas a través de pinturas de naturaleza tipográfica. El tiempo compartido durante la estancia en Paraguay ha dado como resultado la edición de un documento audiovisual con 21 entrevistas, la realización de 21 pinturas, retratos tipográficos, y la recogida de centenares de retratos que han hecho los niños y las niñas del Paraguay a sus maestras.

Destacamos las quejas y reclamos de las docentes, que coinciden con las reivindicaciones de las mujeres artesanas del país, investigadas por Germán Navarro Espinach (2019) en una acción paralela, quienes solicitan recibir más atención, tanto económica como laboral, y también un reconocimiento por su aportación a la educación y a las artes. El bagaje cultural paraguayo está tremendamente vinculado a la artesanía, lo que nos acerca a reflexiones estéticas, culturales, económicas, históricas y políticas. Estamos a tiempo de celebrar las diversidades, tanto de las maestras como de las artesanas de este país poco conocido que es Paraguay, y serán las autoridades públicas quienes tendrán la última decisión para apoyar tanto a las unas como a las otras, a las maestras y a las artesanas. En última instancia, se trata de las mujeres, un elemento esencial de nuestra sociedad.

\section{Conclusiones}

En la presente investigación partimos de la idea que nos ha acompañado desde siempre en el proyecto Mujeres Maestras: dar visibilidad al colectivo de las docentes. Este objetivo es común a toda la trayectoria del proyecto, pero ha tenido particularidades propias en cada uno de los países donde se ha llevado a cabo. En anteriores estudios habíamos indicado los logros conseguidos, pero en esta ocasión el reto era mayor, ya que Paraguay es una realidad poco conocida, a diferencia de otros países cuya presencia es relevante a nivel mediático, político y económico.

Paraguay ha renacido de las cenizas gracias a las mujeres al menos dos veces en la historia: tras la guerra de la Triple Alianza y después de la guerra del Chaco. En ambos casos, fueron las mujeres las que originaron este renacimiento. Las mujeres de este país son las máximas responsables de este doble renacimiento, ya que en ambos casos la gran 
mayoría de hombres adultos murieron en las batallas o fueron exterminados. Sin idealizarlas, aunque sin eliminar su importante papel en el espacio público, lo que podemos hacer es reconocer su esfuerzo, honrarlas por su trabajo y transmitir estas enseñanzas a niños y niñas a través de este tipo de actividades artísticas y de exhibición.

Es lo que intentamos con el proyecto Mujeres Maestras del Paraguay: concienciar a las personas de la importancia que tienen las mujeres que se dedican a la enseñanza. Lo hacemos mediante expresiones artísticas, pinturas, videos y dibujos que son realizados por artistas, alumnado y siempre con la participación activa de las propias maestras. Queremos hacer visible el trabajo de las mujeres, dignificarlo y apoyarlo. También continuamos las investigaciones a partir del análisis de los dibujos realizados por el alumnado, quienes retratan a sus maestras. Estos trabajos son estudiados como realidad palpable de la imagen que generan de sus maestras. Los resultados del proyecto, tanto desde la vertiente de la exposición como desde la recopilación de dibujos y de las entrevistas a maestras, son difundidos a través de artículos en revistas especializadas y de libros sobre la temática, de modo que continuamos atendiendo con interés la realidad atractiva y muy recomendable del quehacer y la labor constante de las maestras.

Cerramos esta contribución agradeciendo la enorme hospitalidad y afecto con que nos han recibido en este país de contrastes y naturaleza. Transmitimos poéticas reivindicativas y culturales, algo que es muy necesario si pretendemos lograr una sociedad más justa y equitativa, más respetuosa y más libre. 


\section{Referencias}

Albero, S. A. y Arriaga, A. (2018). Educación con Perspectiva de Género en Museos Españoles. Enfoques y Discursos. Géneros. Multidisciplinary Journal of Gender Studies, $\quad 7(1), \quad$ 1531-1555. Recuperado de http://dx.doi.org/10.4471/generos.2018.2921.

Alonso, A. (2016). Conciliación de la vida estudiantil, familiar y laboral de una madre universitaria. Revista de Antropología Experimental, (16), 223-233.

Alonso, A., Jardón, P. and Lifante, Y. (2019). The role of the classroom's images. Study of visual culture at three schools. Visual Studies, 34(2). Retrieved from tandfonline.com/doi/abs/10.1080/1472586X.2019.1653223? journalCode=rvst20.

Álvarez, L. (2019). Modelos teóricos de implicación educativa familiar: responsabilidades compartidas entre centros educativos, familias y comunidad. Aula Abierta, 48(1), 19-30. Recuperado de http://dx.doi.org/10.17811/rifie.48.1.2019.19-30.

Capdevila, R. (2016). Julián y Josefina: de la indagación americanista al descubrimiento del arte popular paraguayo. Cuadernos Salazar, (4), 28-33.

Carr, W. and Kemmis, S. (2009). Educational Action Research: A Critical Approach. In Noffke, S. E. and Somekh, B. (eds.), Sage Handbook of Educational Action Research (6 ${ }^{\text {th }}$ ed.) (pp. 74-84). London, England: SAGE Publications Ltd.

Costa, P. (2018). Conversing with Personal Digital Assistants. Journal of Science and Technology of the Arts, 10(3), 59-72. Retrieved from 10.7559/citarj.v10i3.563.

Dewey, J. (2008) El arte como experiencia. Barcelona, España: Paidós.

Donaire, R. (2012). Los docentes en el siglo XXI: ¿empobrecidos o proletarizados? Buenos Aires, Argentina: Siglo XXI Editores.

Duncum, P. (2015). Transforming Art Education into Visual Culture Education through Rhizomatic Structures. Anadolu Journal of Educational Sciences International, 5(3), 47-64. Retrieved from 10.18039/ajesi.66849.

El Haddad, K., Rizk, Y., Heron, L., Hajj, N., Zhao, Y., Kim, J., Trọng, T. N., Doumit, M., Lin, P., Kim, Y. and Çakmak, H. (2018). End-to-End Listening Agent for Audiovisual Emotional and Naturalistic Interactions. Journal of Science and Technology of the Arts, 10(2), 49-61.

Elliott, J. (1991). Action Research for Educational Change. London, England: McGrawHill. 


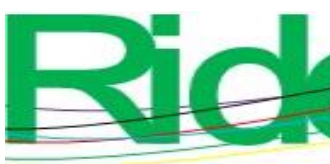

Escobar, T. (2011). El mito del arte y el mito del pueblo. Cuestiones sobre arte popular. Asunción, Paraguay: CAV Museo del Barro.

Eustáquio, L. (2017). Interference modalities for interaction and performance design. Journal of Science and Technology of the Arts, 9(3), 71-82. Retrieved from https://revistas.ucp.pt/index.php/jsta/article/view/7296.

Freire, P. (2015). Pedagogia da autonomia: saberes necessários à prática educativa. Rio de Janeiro, Brasil: Paz e Terra.

Giroux, H. (2013). La pedagogía crítica en tiempos oscuros. Praxis Educativa, 17(17), 13-26.

Giroux, H. (2015). Education and the Crisis of Public Values: Challenging the Assault on Teachers, Students, and Public Education. Oxford, United Kingdom: Peter Lang.

Greteman, A. J. (2017). Helping Kids Turn Out Queer: Queer Theory in Art Education. Studies in Art Education, 58(3), 195-205. Retrieved from 10.1080/00393541.2017.1331089.

Hamlin, J. and Fusaro, J. (2018). Contemporary Strategies for Creative and Critical Teaching in the 21st Century. Art Education, 71(2), 8-15. Retrieved from https://doi.org/10.1080/00043125.2018.1414529.

Hernández, F. (2008). La investigación basada en las artes. Propuestas para repensar la investigación en educación. Educatio Siglo XXI, 26, 85-118.

Hernández, R., Pacheco, B., Liranzo, P. y Jiménez, A. (2018). "Yo quería ser...”: la voz de maestras de educación primaria. Ciencia y Educación, 2(1), 51-59. Recuperado de http://dx.doi.org/10.22206/cyed.2018.v2i1.pp51-59.

Huerta, R. (2012). Mujeres Maestras. Identidades docentes en Iberoamérica. Barcelona, España: Graó.

Huerta, R. (ed.) (2018). Mujeres maestras del Perú. Lima, Perú: Pontificia Universidad Católica del Perú.

Huerta, R. (2019). Arte para primaria. Barcelona, España: UOC.

Huerta, R., Alonso, A. y Ramon, R. (eds.) (2018). Investigar y educar en diseño. Valencia, España: Tirant lo Blanch.

Huerta, R., Domínguez, R. y Barbosa, A. M. (2017). Investigar para educar en diseño y otras urgencias de la educación artística. EARI Educación Artística Revista de Investigación,

$10-23$.

Recuperado

de https://ojs.uv.es/index.php/eari/article/view/10790/10177. 
Irwin, R. (2013). Becoming A/R/Tography. Studies in Art Education. A Journal of Issues and Research, 54(3), 198-215.

Kunhardt, E. (2020). Invención dentro del curriculum: sugerencias de un innovador. Ciencia y Educación, 3(3), 43-52. Recuperado de https://doi.org/10.22206/cyed.2019.v3i3.pp43-52.

Lucas, L., Trabajo, M. y Borghi, B. (2020). El museo como laboratorio escolar. Análisis de buenas prácticas. Arte, Individuo y Sociedad, 32(2), 299-317. Recuperado de https://doi.org/10.5209/aris.63288.

Melo de Lima Santos, Z. M. (2017). Escola como espaço de transformação: a articulação da educação, pobreza e desigualdade social no currículo escolar. Revista Internacional de Investigación en Ciencias Sociales, 13(2), 239-252. Recuperado de http://dx.doi.org/10.18004/riics.2017.diciembre.239-252.

Méndez, P. (2016). Constitución de sujeto maestro en prácticas de resistencia en Colombia. Enunciación, 21(1), 15-30.

Monterroza, V., Buelvas, U. J. y Urango, J. (2019). Arte, creatividad y cultura en infantes. Ciencia y Educación, 3(2), 37-46. Recuperado de https://doi.org/10.22206/cyed.2019.v3i2.pp37-46

Navarro Espinach, G. (2019). La reivindicación de los oficios artesanales del Paraguay. Revista científica Omnes, 2(1), 28-47.

Ramon, R. (2019). Prácticas artísticas de visualización entre cuerpo y objeto en entornos de mediación pedagógica. Arte, Individuo y Sociedad, 31(13), 509-526. Recuperado de http://dx.doi.org/10.5209/aris.60881.

Rivas, J. I., Hernández, F., Sancho, J. M. y Núñez, C. (coords.) (2012). Historias de vida en educación: Sujeto, diálogo, experiencia. Barcelona, España: Red Universitaria de Investigación e Innovación Educativa.

Rolling, J. H. (2017). Arts-Based Research in Education. In Leavy, P. (ed.) Handbook of Arts-Based Research (493-510). New York, United States: Guilford.

Secretaría Nacional de Cultura. (2016). Más allá de la Guerra. Aportes para el debate contemporáneo. Asunción, Paraguay: Libros del Ocaso.

Sennett, R. (2008). The Craftsman. New Haven, United States: Yale University Press.

Stake, R. E. (1995). The Art of Case Study Research. London, England: Sage.

Zafra, R. (2017). El entusiasmo. Precariedad y trabajo creativo en la era digital. Barcelona, España: Anagrama. 